\title{
Cuba: un número clave en la combinación del Caribe
}

Johnny Cova S.

\section{La politica externa latinoamericana de los Estados Unidos: un fracaso}

Estamos viviendo tiempos de cambios drásticos en la estructura del poder en el área del Caribe. Justamente veinte años después del último cambio significativo en esta estructura, protagonizado por Fidel Castro en Cuba, surgen movimientos revolucionarios en Nicaragua, El Salvador y Granada, que nuevamente tienden a poner en jaque el poder predominante de los Estados Unidos en el Caribe. Pero los movimientos de liberación nacional son solamente los actores más destacados de un drama que incluye la intensificación del enfrentamiento norte-sur debido al problema global de la deuda externa de los países del tercer mundo y a la derrota del modelo de desarrollo ejemplificado por gobiernos militares de derecha.

No hay duda alguna de que los Estados Unidos perdieron su posición privilegiada en el Caribe a causa de la revolución socialista cubana de 1959. A través de Cuba, la Unión Soviética ha logrado contrarrestar las aspiraciones hegemónicas de los Estados Unidos en la región. Pero Cuba no ha sido el único factor que ha incidido en el debilitamiento del poder político estadunidense en América Latina y, particularmente, en la cuenca del Caribe.

Partiendo de la época posterior a la Segunda Guerra Mundial, la influencia de los Estados Unidos en América Latina ha sufrido un desgaste ideológico debido fundamentalmente a su actuación en materia económica y política. Aun existiendo un resentimiento latente por la continua interferencia de los gobiernos estadunidenses en los asuntos internos de los países latinoamericanos, se aspiraba a que una estrecha relación con el "coloso del norte" resultara en un fuerte impulso al desarrollo económico del área. Pero nunca llegó el desarrollo. Las grandes corporaciones norteamericanas repatriaron la mayor parte de sus utilidades, limitando así el flujo de capital tan necesario para un crecimiento sostenido de las economias subdesarrolladas. ${ }^{1}$ La Alianza para el Progreso y, en general, la ayuda económica prestada a los países subdesarrollados del hemisferio occidental, no dieron los resultados esperados, ya que las motivaciones estaban fundamentalmente relacionadas con la política de contención, adoptada por Washington a partir de la década de los cincuenta. ${ }^{2}$ Por otro lado, habria que considerar la creciente desigualdad en los términos de intercambio, entre ma-

' Raymond Aron, The Imperial Republic: The United States and The World, 1945-1973, Cambridge, Winthop Publishers, 1974, p. 247.

${ }^{2}$ Ibid., p. 174-5, 220. Según Aron, la política de contención debe ser interpretada desde una perspectiva amplia que se propone asegurar las condiciones favorables para las ideas, bienes e inversiones de los Estados Unidos en el mundo. 
teria prima y bienes manufacturados, en detrimento de las economías generalmente monoproductoras de América Latina y el área del Caribe. ${ }^{3}$ Sumando a estos hechos el papel desempeñado por el reciclaje de petrodólares en manos de la banca privada estadunidense, en forma de préstamos a corto plazo y a tasas de interés variable, culminamos con el resultado catastrófico de la gigantesca deuda externa que asciende actualmente a un monto de aproximadamente US $\$ 360$ mil millones.

En la esfera política el desgaste de la hegemonia estadunidense ha sido mayor, y se puede atribuir, principalmente, al papel predominante que le ha otorgado Washington al enfoque este-oeste en sus relaciones interamericanas. Esta perspectiva conlleva una visión en blanco y negro de los procesos políticos y sociales de América Latina. Tiende al mantenimiento del statu quo que ha llevado a los Estados Unidos a aliarse con ellos o a aceptar pasivamente regimenes dictatoriales represivos, mientras que participa activamente en el derrocamiento de regímenes de izquierda o de carácter reformista confundiendo generalmente, movimientos nacionalistas con una conspiración internacional comunista. ${ }^{4}$

Consideraciones estratégicas llevaron a los Estados Unidos a apoyar al Reino Unido en su intervención aeronaval contra Argentina en las islas Malvinas. Esto ocurrió a pesar del Tratado Interamericano de Ayuda Reciproca (TIAR) y del postulado fundamental de la doctrina Monroe, ${ }^{5}$ y condujo al mayor golpe contra la credibilidad de la política exterior de los Estados Unidos en América Latina.

\section{Problemas en el "patio trasero"}

La situación socioeconómica que presentan la mayoría de los países caribeños y que se caracteriza por altas tasas de desempleo, inflación y probreza extrema, tiende a propiciar el descontento popular que crea condiciones favorables para el surgimiento de gobiernos nacionalistas y movimientos revolucionarios de izquierda. ${ }^{6}$ Ante el fracaso del modelo de desarrollo capitalista auspiciado por los Estados Unidos, que ha beneficiado principalmente a las pequeñas oligarquias gobernantes y que ha resultado en un sometimiento de las masas a los criterios de austeridad del

\footnotetext{
${ }^{3}$ Consecuencia secundaria de la caida en los precios internacionales es la fuga de capital extranjero. Por lo menos cinco compañias internacionales cerraron sus actividades en el Caribe debido a la caída en los precios de la bauxita, el azúcar, los cambures y el petróleo: éstas son: Alcoa y Reynolds, en Jamaica y República Dominicana: Gulf \& Western en República Dominicana; United Brands en Costa Rica y la Exxon en Aruba respectivamente. Véase: Andrés Oppenheimer, Miami Herald. 3 de marzo de 1985.

${ }^{4} \mathrm{Al}$ respecto un senador demócrata estadunidense señaló que "...nuestro problema... está en nuestra dificultad para comprender que las revoluciones en el Tercer Mundo son primordialmente nacionalistas, no comunistas. Nacionalismo, no capitalismo ni comunismo, es la fuerza política dominante en el mundo moderno". Véase Frank Church, Los Angeles Times, 11 de marzo de 1984.

${ }^{3} \mathrm{La}$ doctrina fue esbozada por el presidente James Monroe en 1823 y ha sufrido modificaciones a través del tiempo, pero su postulado principal se refiere a la inaceptabilidad de interferencia de países europeos en los asuntos hemisféricos.

- Esta situación ha sido especialmente crítica en Centromérica. De acuerdo con la Comisión Económica para América Latina. más del $60 \%$ de la población de la región vive en pobreza y más del $40 \%$ en extrema pobreza. Véase: Cristopher Dodd, Los Angeles Times, 28 de marzo de 1985.
} 
Fondo Monetario Internacional. el modelo de desarrollo cubano comienza a vislumbrarse como una alternativa viable.

La revolución socialista cubana, bajo la dirección de Fidel Castro, ha logrado acrecentar la respetabilidad del régimen ante la comunidad de naciones latinoamericanas durante el último cuarto de siglo, por una razón muy sencilla: aún persiste, a pesar de la oposición de los Estados Unidos. Oposición que se ha manifestado en apoyo gubernamental a la invasión de Cuba por exiliados armados, al establecimiento de un inflexible embargo económico y. al lanzamiento de una estación radial antigubernamental dirigida a Cuba y operada por exiliados cubanos en Miami. ${ }^{7}$

Los Estados Unidos, a través de la Doctrina Monroe y el Corolario Roosevelt de la misma, han impuesto unilateralmente en América una especie de "derecho internacional" basado en la fuerza que le otorga poderes policíacos especiales por encima de la soberanía de los Estados americanos. Basados en esta doctrina, los Estados Unidos han participado activamente en el derrocamiento de los gobiernos de México (1913), Guatemala (1954), Brasil (1964), República Dominicana (1965), Chile (1973) y Granada (1983); y actualmente intentan el derrocamiento del gobierno de Nicaragua. Aun cuando el término "Doctrina Monroe" ha entrado en desuso por los resentimientos antimperialistas que desata, funcionarios gubernamentales estadunidenses todavía se refieren a Centroamérica y a los países del Caribe como a su "patio trasero".

La mayoria de los latinoamericanos rechazan la arrogancia con que los Estados Unidos han manipulado a su antojo los asuntos internos de sus respectivos países, pero al mismo tiempo aspiran a alcanzar un nivel de desarrollo parecido al norteamericano. Esta relación amor-odio puede ser, y ha sido, explotada por Fidel Castro en su lucha contra el aislamiento al cual ha sido sometida Cuba en el hemisferio por los Estados Unidos. Esta lucha se está librando en todos los frentes; pero tiene especial significado en el campo político, ideológico y militar, ya que los resultados del enfrentamiento en estos campos inciden directamente en la correlación de fuerzas en la Cuenca del Caribe.

\section{La política exterior cubana: prudencia y discreción}

A medida que Fidel Castro se acerca a los 60 años de edad, parecería que está logrando uno de sus grandes objetivos en la escena internacional: el reconocimiento diplomático de Cuba por los paises latinoamericanos que se unieron al embargo diplomático y comercial impuesto por los Estados Unidos en 1964. De lograrse, esto pondría a Cuba en la antesala de la Organización de Estados Americanos (OEA) y sería un duro golpe a la política de confrontación esbozada por la administración Reagan.

Si analizamos la evolución de la política exterior cubana en los últimos veintisiete años, es inevitable concluir que ha venido de-

\footnotetext{
'Nos referimos aqui a Radio Marti, estación auspiciada por el gobierno estadunidense, que inició sus transmisiones el 20 de mayo de 1985 . El director de la estación. Jorge Mas, es veterano de la invasión de bahía de Cochinos. Véase: Latin timerican W'ekly Report. WR-85-21.31 de mayo de 1985.
} 
sarrollándose en una forma coherente que, aparentemente, apunta hacia un proceso de maduración del principal autor de la misma: Fidel Castro. En parte, el éxito de la política exterior cubana puede atribuirse a una cualidad extraordinaria de Castro, quien no sólo percibe los grandes temas de la política latinoamericana, sino que también los explota en prosecución de los intereses cubanos. Prueba de ello ha sido el interés especial de Castro en relación con el nuevo orden económico internacional, la guerra de Las Malvinas y la deuda externa de los países latinoamericanos.

Es posible percibir en la evolución de la política exterior cubana un periodo inicial caracterizado por el fervor revolucionario que culmina con la muerte del "Che" Guevara en Bolivia en 1967. Durante este periodo, Cuba apoyó abiertamente movimientos guerrilleros que aspiraban al derrocamiento de gobiernos latinoamericanos. Aun cuando esta política sirvió para crear los lazos amistosos que aún persisten entre Cuba y los movimientos revolucionarios de izquierda, el resultado inmediato fue su aislamiento comercial y diplomático. La década de los setenta inicia un nuevo rumbo en la política exterior cubana. ${ }^{8}$ Este nuevo rumbo surge de una revisión crítica de los errores del pasado, y se dirige hacia la elaboración de una política externa cónsona con los preceptos marxistas y leninistas de la revolución cubana, evitando, al mismo tiempo, la confrontación con los gobiernos regionales. Los tres objetivos básicos de esta política eran y siguen siendo, superar las dificultades impuestas por el embargo, lograr una legitimidad externa del gobierno cubano por vía de la diplomacia y mantenerse a la vanguardia de la lucha ideológica tercermundista. Alcanzar estos objetivos, en un periodo relativamente corto, implicaría la implantación de una política exterior más pragmática y capaz de conciliar los intereses nacionales con una orientación ideológica marxista y leninista.

Para asegurar la supervivencia de la revolución cubana se hacia indispensable continuar recibiendo la ayuda económica de la Unión Soviética y, al mismo tiempo, evitar una invasión armada estadunidense. Esto último indujo a una política exterior que se puede caracterizar por el ejercicio de la prudencia y la discreción ante el poderio militar y económico de los Estados Unidos. Pero entablar nuevamente relaciones diplomáticas y comerciales con los países de la región exigía superar tres importantes obstáculos: el rechazo general a la política cubana de exportación de la revolución, la existencia de gobiernos militares de derecha opuestos al régimen socialista cubano y la influencia ejercida por los Estados Unidos sobre la mayoria de los gobiernos americanos.

El fracaso de la politica de exportación de la revolución culminó en la restricción del apoyo a los movimientos guerrilleros latinoamericanos y se manifestó en la instrumentación de una política "estadista" que marca el inicio de la segunda etapa evolutiva de la política exterior cubana. Como lo apuntó Castro en una entrevista en 1975:

...No es que no simpatizamos con los movimientos revolucionarios.

${ }^{8}$ Demetrio Boersner, "Una Estrategia tercermundista para el Caribe", Nueva Sociedad, núm. 37 , julio-agosto, 1978 , p. 58. 
Simpatizamos, si. Ahora, si surge un movimiento revolucionario en un pais que tiene relaciones con nosotros, o que respete nuestra soberanía y nuestro país, por mayor que sea nuestra simpatía por los movimientos revolucionarios, nosotros nos abstendremos de cualquier apoyo a ese movimiento. Esa fue y continúa siendo nuestra política. ${ }^{9}$

La presencia mayoritaria de gobiernos militares de derecha en América Latina en la década de los setenta, representaba un obstáculo mayor para la consecución de los intereses nacionales cubanos. ${ }^{10} \mathrm{Al}$ haber rechazado el apoyo directo a los movimientos revolucionarios, se disponía únicamente de los medios diplomáticos e ideológicos. En este sentido, la política externa cubana opta por fortalecer el proceso de desarrollo interno bajo el modelo socialista con la finalidad de plantear, ante la comunidad latinoamericana y del Caribe, una alternativa viable al modelo de desarrollo capitalista dependiente; ampliar las actividades propagandisticas en la región, a fin de resaltar los logros de la revolución cubana, y extender por los medios diplomáticos los lazos dé colaboración entre Cuba y los países latinoamericanos y del Caribe, en las áreas de salud, educación y cultura. Simultáneamente, se inicia un acercamiento con los países democráticos capitalistas bajo el principio del pluralismo ideológico. ${ }^{11}$

Estas medidas, por supuesto, pretenden minar la influencia de los Estados Unidos en el hemisferio; en ellas Fidel Castro ha contado con un excelente aliado: el gobierno de los Estados Unidos. Es tradición de la política latinoamericana basarse, fundamentalmente, en su arrollador poder económico y militar, y no en su conocimiento, aún superficial, de la realidad socioeconómica latinoamericana. Arthur Schlesinger Jr. señaló este hecho cuando dijo que "...una vía alterna al problema centroamericano comenzaría por tratar de entender la situación latinoamericana, en términos latinoamericanos en vez de imponer nuestras obsesiones globales sobre una región con una historia, conciencia y orgullo propio..."12 Howard Wiarda también ha criticado el uso persistente de un modelo equivocado como marco de la política exterior latinoamericana de los Estados Unidos. ${ }^{13}$ Este modelo, basado en la tradición liberal norteamericana, incurre en la falacia de intentar aplicar el modelo de desarrollo norteamericano en América Latina. Castro ha capitalizado los errores cometidos por las administraciones estadunidenses y, especialmente, por aquellos cometidos en la pre-

' Fernando Morais, La isla: Cuba y los cubanos Hoy, México, Nueva Imagen, 1978, p: 148.

10 Al contrario, en lo que va de esta década se ha visto la vuelta a gobiernos democráticos en El Salvador, Honduras, Bolivia, Uruguay, Argentina y Brasil.

"En una entrevista, Fidel Castro se refirió a esta política diciendo: "...nosotros estamos dispuestos a atenernos ciento por ciento: no inmiscuirnos, aunque simpaticemos con los movimientos revolucionarios, ni inmiscuirse Estados Unidos ni Cuba, que cada país decida con entera responsabilidad qué sistema político y económico debe seguir, que nadie trate de promover un nuevo sistema social desde el exterior. ni de mantener un orden social injusto." Fidel Castro, Sobre la deuda impagable de America Latina. sus consecuencias imprevisibles y otros temas de interés politico e histórico, entrevista concedida a la agencia EFE, La Habana, Editora Politica, 1985, p. 97. Véase también a Latin American Weekly Report, WR-85-26, 1985 , p. 6.

12 Arthur Schlesinger, The Wall Street Journal, 21 de mayo de 1984.

${ }^{13}$ Howard Wiarda, Los Angeles Times, 6 de mayo de 1984. 
sente administración del Sr. Ronald Reagan.

Como ya hemos señalado, el principal error de Reagan ha sido una visión empañada por el conflicto este-oeste. El interés por América Latina sólo aparece ante lo que se considera una amenaza comunista en el hemisferio. Es así como la Alianza para el Progreso surge inmediatamente después de la revolución cubana, a pesar de que mucho antes el presidente Kubitschek de Brasil había abogado por la implantación de la Operación Panamericana. Después de los acontecimientos de Nicaragua y Granada, surge la Iniciativa de la Cuenca Caribeña ${ }^{14}$ y se incrementa la ayuda económica y militar a Centroamérica de US $\$ 336$ millones en 1980 a US $\$ 881$ millones en 1984 , de los cuales US $\$ 482$ millones estaban destinados a Honduras, El Salvador y Costa Rica; es decir, los países vecinos de Nicaragua. Granada, con una población menor de 120 mil habitantes, recibió US $\$ 47$ millones. ${ }^{15}$ Por otro lado, los precios internacionales de las materias primas siguen bajando, se aumentan los obstáculos arancelarios a la importación en los paises capitalistas desarrollados, y el peso de la deuda externa de los países latinoamericanos y del Caribe llega a un punto insoportable. Esta situación obliga a una restricción a la libre convertibilidad de divisas, un debilitamiento en la capacidad de inversión de los Estados y a reformas fiscales que, en conjunto, desestimulan la inversión extranjera.

Fidel Castro ha podido manejar con éxito, en su lucha ideológica, estos errores y omisiones en la política exterior latinoamericana de los gobiernos estadunidenses. Dentro del movimiento de los no alineados, ha sido el abanderado del nuevo orden económico internacional. Durante la guerra anglo-argentina de las islas Malvinas, dio un fuerte apoyo a la causa argentina cuando los Estados Unidos, en actitud vacilante terminaron finalmente, apoyando a Inglaterra. Actualmente, es el vocero extraoficial de los pueblos latinoamericanos en el problema de la deuda externa. Al respecto. Castro dice lo que los demás gobiernos no se atreven a decir. En tal sentido, ha planteado que la deuda externa latinoamericana es impagable, y propone que el gobierno de los Estados Unidos utilice dinero del presupuesto de la defensa para cancelar los bancos acreedores y asi evitar las "explosiones sociales" hemisféricas del futuro cercano. Parece contradictorio, Castro ayudando al sistema bancario capitalista; pero, ante la opinión pública de América Latina y el Caribe, es Fidel Castro quien trata de evitar las consecuencias catastróficas del problema, mientras que el presidente de los Estados Unidos se ocupa de los "contras" y la Guerra de las Galaxias. Como lo mencionó Ted Szulk recientemente: “...los Estados Unidos, que han trabajado tan duro todos estos años para mantener a los cubanos aislados, ahora se encuentran crecientemente alienados en el hemisferio porque los latinoamericanos están convencidos que a la Casa Blanca de Reagan no le importa su terrible crisis económica mientras que a Castro sí." 16

14 El "Caribbean Basin Initiative (CB1)" entró en vigor el 1 de enero de 1984. Ofrece estímulos fiscales y arancelarios a la inversión norteamericana en los países de la Cuenca del Caribe por un periodo de doce años. Cuba y Nicaragua están excluidos del programa.

is Roger Lowenstein, Wall Street Journal, 3 de diciembre de 1984.

16 Ted Szulk, New York Times, 5 de mayo de 1985. 
La política de Reagan en Centroamérica, por supuesto, ha sido fundamental en el éxito diplomático de la política externa cubana. El embargo a Nicaragua y la reciente petición de US\$100 millones para los "contras", sólo ha demostrado que el gobierno de los Estados Unidos insiste en imponer una solución militar unilateral, a pesar del visto bueno internacional que se le ha dado al Grupo de Contadora, en su búsqueda de una solución pacífica y negociada en Centroamérica. ${ }^{17}$

Ante este panorama no es sorprendente que Fidel Castro al fin esté superando la capacidad de persuasión de los Estados Unidos en América Latina. Capitalizando el descontento general con la política latinoamericana del presidente Reagan, Cuba discretamente se convierte en catalizador de un movimiento latinoamericano independiente. Carlos Rafael Rodríguez, vicepresidente cubano, dijo en una ocasión:

El problema de Latinoamérica en este momento es el problema de cohesión y coordinación entre los gobiernos latinoamericanos, aun cuando tengan puntos de vista diferentes sobre política y economía, a fin de establecer la capacidad de Latinoamérica para negociar con otras partes del mundo, incluyendo a los Estados Unidos. ${ }^{18}$

La evidencia señala que la mayoría de los gobiernos latinoamericanos están de acuerdo. Solamente 14 países de los 32 miembros de la Organización de Estados Americanos no mantienen, en la actualidad, relaciones amistosas con Cuba. ${ }^{19}$ En junio de 1985 Cuba fue admitida al Parlamento Latinoamericano con 15 votos a favor y 2 en contra (Paraguay y El Salvador), en lo que un diplomático europeo llamó el mayor triunfo de la política exterior cubana desde que los Estados Unidos originaron su aislamiento hemisférico en $1964 .^{20}$ Puede inferirse que, perteneciendo ya al Parlamento Latinoamericano, la readmisión de Cuba a la Organización de Estados Americanos es sólo cuestión de tiempo.

\section{Una potencia militar en el caribe}

Cuba no sólo ha logrado establecer una importante presencia en América Latina y el Caribe en el ámbito diplomático e ideológico, sino también en el ámbito militar. Esto, por supuesto, no es de sorprender dada la corta distancia que separa a Cuba de su principal enemigo: los Estados Unidos. Pero también es cierto que la actitud amenazadora que ha asumido la Casa Blanca en el pasado, y especialmente bajo la administración Reagan, ha contribuido a la militarización de la sociedad cubana. ${ }^{21}$ De hecho, el entonces

${ }^{17}$ El Grupo de Contadora, creado en 1983, está integrado por México, Panamá, Colombia y Venezuela. Recientemente se le unieron como grupo de apoyo Argentina, Brasil, Uruguay y Perú.

${ }_{18}$ Robert Scheer, Los Angeles Times, I de enero de 1984.

19 Los países que no tienen relaciones con Cuba son: Belice, Guatemala, Honduras y Costa Rica en Centroamérica; Jamaica, Haiti, República Dominicana, St. Kitts. Antigua. Dominica y San Vicente en el Caribe; Paraguay y Chile en Sudamérica: y los Estados Unidos.

2) Sam Dillon, Miami Herald. 1 de agosto de 1985.

"Wayne S. Smith, jefe de la Sección de Interés de los Estados Unidos en La Habana en el periodo 1979-1982, ha documentado ampliamente el papel protagonizado por los Estados Unidos que resultaron en las intervenciones cubanas en Africa y la creación de la Milicia Territorial. Véase: Wayne S. Smith, "Dateline Havana: Myopic Diplomacy", Foreign Policy, núm. 48, 1982, p. 157-174. 
secretario de Estado, Alexander Haig, declaró en febrero de 1981 que "la actividad cubana ha alcanzado un pico que ya no es aceptable en este hemisferio... El Salvador es un problema que emana primero y principalmente de Cuba y... es nuestra intención tratar este asunto en su origen."

Las Fuerzas Armadas Revolucionarias (FAR) cuentan actualmente con 160 mil efectivos en las tres fuerzas y 135 mil reservistas experimentados. Además, la Milicia Territorial cuenta con más de un millón de ciudadanos entrenados en el uso del rifle de asalto AK-47 y en el lanzamiento de granadas. El objetivo de la Milicia es ocupar y nroteger los vecindarios en caso de una invasión estadunidense. ${ }^{23}$ Esto hace de las FAR el mayor ejército de Latinoamérica y del Caribe, superando inclusive a las Fuerzas Armadas Brasileñas. Bajo el mando de Raúl Castro (hermano de Fidel), las Fuerzas Armadas Revolucionarias, con pertrechos soviéticos, han logrado obtener una capacidad ofensiva limitada pero única en Centroamérica y el Caribe. El ejército cuenta con más de 950 tanques medianos tipo T-62, equipo antiaéreo que incluye instalaciones SA-3, artilleria pesada de $130 \mathrm{~mm}$ y armas antitanque. La fuerza aérea, superada en el hemisferio sólo por los Estados Unidos, cuenta con más de 200 aviones caza que incluyen por lo menos 35 modernos MIG-23, aereotransportadores del tipo AN-26, helicópteros de asalto tipo MI-24 Hind-D y 208 instalaciones de misiles antiaéreos. Las fuerzas navales cuentan con más de 100 embarcaciones que incluyen 3 submarinos de ataque tipo Foxtrot, 2 fragatas, cruceros con misiles, más de 50 patrulleros, barreminas, 2 buques de desembarque anfibio y otras embarcaciones menores y el barco mercante "Isla de la Juventud" que ha sido equipado para la recopilación de inteligencia. ${ }^{24}$

Una reciente publicación conjunta del Departamento de Estado y el Departamento de Defensa de los Estados Unidos afirma que:

La Fuerza Aérea Cubana y la flota aérea comercial podrían transportar por lo menos 15000 soldados a cualquier sitio de la Cuenca del Caribe dentro de dos o tres semanas. Elementos importantes de esta fuerza podrian estar emplazados en pocas horas. Ningún país de la Cuenca, excepto los Estados Unidos, posee los medios para repeler semejante ataque sin asistencia externa. ${ }^{25}$

La proyección cubana a nivel mundial, fundamentada en la política de apoyo hacia el cambio revolucionario en el Tercer Mundo, ha tenido especial importancia en la esfera militar. A partir de 1975, con la llegada de los primeros soldados cubanos a Angola. se ha incrementado la presencia cubana en Africa. A principios del año pasado, Fidel Castro admitió en una entrevista que 200000 soldados y civiles cubanos han servido en Angola, donde

$\because$ Wayne S., "U.S. Policy: The Worst Alternative Syndrome", SAIS Review, vol. 3, núm. 2, 1983, p. 17.

"3 Joseph B. Treaster, New York Times, 23 de junio de 1985; y Edward Cody, Washington Post, 10 de julio de 1985.

24 "Soviet Military Supplies to Cuba", Miami Herald, 10 de abril de 1984; David Thomas, Miami Herald, 29 de abril de 1984; Alfonso Chardy, Miami Herald, 27 de enero de 1984.

${ }_{25}$ U.S. Department of State and Department of Defense, The Soviet-Cuban Connection in Central America and the Caribbean, Washington D.C., 1985, p. 6. 
Cuba mantiene una fuerza de aproximadamente 30000 hombres. ${ }^{26}$ Evaluaciones del Departamento de Estado de los Estados Unidos señalan que, a finales del año pasado, había 44000 efectivos, entre tropas y asesores, en Angola, Etiopia, Mozambique, Congo, Sao Tome, Guinea-Bissau, Tanzania y Nicaragua. ${ }^{27}$ De primordial importancia, por supuesto, ha sido la experiencia de combate de las fuerzas cubanas en Etiopia, Nicaragua y Angola. Por ello, la administración Reagan reconoce que "por medio de sus operaciones en Africa en la última década, Cuba ha obtenido la más extensiva y la más reciente experiencia de combate que cualquier otro país del hemisferio occidental."28

Además del potencial bélico cubano, la Unión Soviética mantiene una presencia militar permanente en la isla y, ocasionalmente, realiza maniobras aeronavales conjuntas con las FAR. La presencia permanente está constituida por una brigada de combate de 2800 efectivos, un contingente de 2800 asesores militares y 2100 técnicos. Estos últimos laboran en la gigantesca instalación de espionaje electrónico ubicada en Lourdes, cerca de La Habana. Varios aviones de reconocimiento del tipo Bear D operan desde bases permanentes en Cuba. ${ }^{29}$

\section{La relación Cuba-URSS}

La relación de Cuba con la Unión Soviética, ha sido sin duda, uno de los problemas más delicados con que Fidel Castro ha tenido que enfrentarse. El dilema lo caracterizó un exdiplomático norteamericano cuando dijo "pobrecita Cuba, atada entre dos superpotencias: una su enemigo mortal y la otra su aliado mortal."30 Existe una polémica sobre las intenciones prerrevolucionarias de Fidel Castro, en relación con el vuelco que le dio a la revolución cubana para orientarla hacia un régimen socialista aliado a Moscú. Pero lo cierto es que los hechos obligaron a Castro a buscar ayuda en el bloque soviético, especialmente después de la imposición del embargo comercial y su aislamiento en el hemisferio. Existen dos hechos importantes que influyeron en la evolución y acomodamiento de las relaciones mutuas Cuba-URSS. El primero fue la crisis de los misiles de 1962 y, el segundó, el fracaso de la política de exportación de la revolución y la consecuente modificación de la política exterior cubana.

El mundo entero contuvo la respiración durante varios dias, en octubre de 1962, cuando Nikita Khrushchev y John Kennedy se enfrentaron en Cuba y llevaron al mundo a un paso de la guerra nuclear. Pero de este enfrentamiento surgió un entendimiento que ha gobernado la actuación militar de ambas potencias respecto a Cuba. La Unión Soviética se comprometía a remover sus armas ofensivas (nucleares) y los Estados Unidos a retirar el bloqueo naval y a no invadir la isla. Hasta la fecha, ambas potencias han

26 Jim Hoagland, Washington Post, 6 de febrero de 1985.

2 "Cuba: Tiny Nation Casts Shadow Far Beyond its Border", Los Angeles Times, 6 de diciembre de 1985.

${ }_{28}$ U.S. Department of State, op. cit., p. 6.

29 Ibid., p. 3.

30 John B. Oakes, New York Times, 6 de noviembre de 1985. 
cumplido con el trato ${ }^{31}$ y. ambas han sufrido las consecuencias. Los Estados Unidos se han resignado a la presencia de un país comunista a menos de $150 \mathrm{~km}$ de sus costas y la Unión Soviética se ha resignado a tener un aliado sin capacidad ofensiva, a esa misma distancia de los Estados Unidos. Por ello, el principal valor de Cuba para la URSS estriba en el campo ideológico como modelo alternativo para los países latinoamericanos y del Caribe. Sólo por esta razón, la URSS invierte US\$ 4 mil millones anuales, mediante ayuda directa y en precios por encima del mercado para el azúcar cubano. Cuba recibió garantías contra una invasión norteamericana pero perdió el acceso al mayor mercado del mundo.

El fracaso de la política de exportación de la revolución en América Latina, fue un segundo factor que ayudó a moldear las actuales relaciones Cuba-URSS. Como ya lo hemos señalado, el fracaso revolucionario indujo a Castro a seguir una política discreta, "estadista", con el objeto de obtener el liderazgo en el Tercer Mundo. En esta política estaba implícito el mantener los fuertes lazos cubano-soviéticos en un segundo plano y dar prioridad a la imagen tercermundista, no alineada, del régimen cubano. Este arreglo fue perfectamente aceptable para la URSS, ${ }^{32}$ ya que, en el mejor de los casos, el área del Caribe era, y sigue siendo, de interés periférico, ya que las prerrogativas militares están a favor de los Estados Unidos. En estas circunstancias, la URSS ha optado por una presencia discreta que da la iníciativa al gobierno de Fidel Castro.

Esta politica soviética ha sido mal interpretada por observadores occidentales que acusan a Cuba de ser testaferro soviético en la región, dando crédito a Moscú y no a La Habana por las acciones cubanas en Africa, Nicaragua y Granada. Ilya Bulichev y otros, del Instituto Latinoamericano de la Academia de Ciencias Soviética, consideran que Cuba no es un testaferro soviético en Centroamérica y que, el hambre, la pobreza y la injusticia social inevitablemente darán origen a un conflicto con o sin la intervención de cualquiera de las superpotencias. ${ }^{33}$ Por otro lado, Jorge Dominguez, de la Universidad de Harvard, halló en su análisis de la documentación incautada en la invasión de Granada, que los soviéticos no estaban muy interesados en lo que estaba sucediendo ahí y que los cubanos no habían ofrecido asistencia militar en caso de crisis. Igualmente, encontró que Cuba actuaba como intermediaria, a favor de los granadinos, ante el gobierno soviético. ${ }^{34}$ En otra clara señal de independencia cubana frente a los deseos de la URSS, Fidel Castro recientemente realizó cambios ministeriales aparentemente destinados a preparar el camino para la época posCastro. Los grandes perdedores en la reestructuración fueron los ministros más abiertamente conectados con la ortodoxia soviética y los ganadores, por supuesto, fueron los fidelistas. ${ }^{35}$

${ }^{31}$ El 14 de septiembre de 1984, el presidente Ronald Reagan insinuó que el acuerdo ya no tendría validez. Véase: Wayne S. Smith, New York Times, 1 de octubre de 1984.

32 Es difícil distinguir precisamente si esta política corresponde a iniciativas de Fidel Castro o si simplemente son expresión de la política de distensión inaugurada en la década de los setenta.

${ }^{33}$ Gary Thatcher, Christian Science Monitor, 14 de diciembre de 1984

${ }^{34}$ Lourdes Meluza, Miami Herald, 19 de agosto de 1985.

35 Latin American Weekly Report, RC-85-07, 23 de agosto de 1985. 


\section{Hacia una política externa tercermundista}

Es difícil predecir el rumbo que tomará la revolución cubana en los próximos años, pero dos tendencias se pueden vislumbrar: primero, la influencia cubana en América Latina tenderá a incrementarse en la medida que su politica externa sea capaz de capitalizar los errores y omisiones de la política latinoamericana de los Estados Unidos y, segundo, a medida que transcurra el tiempo se hará más patente la orientación independiente que ha estado siguiendo la politica exterior cubana.

Estas dos tendencias, hasta cierto punto, indican un rumbo que se niega a adaptarse al molde del conflicto este-oeste y que busca su salida más bien en las direcciones contrapuestas: norte-sur. Es la única respuesta lógica al dilema enemigo mortal-aliado mortal al que ha estado atado el pueblo cubano. Esto es fácil de entender, si consideramos que Cuba se encuentra en la encrucijada nortesur, este-oeste; intimamente ligada a un pais con el cual no tiene lazos étnicos, históricos o culturales y aislada, por imposición de los Estados Unidos, de los países con los cuales sí tiene estos lazos. Ante este panorama, no es nada sorprendente la apertura africana a la política exterior cubana. Lo mismo ha estado sucediendo con Brasil. ${ }^{36}$

El restablecimiento de relaciones amistosas con los países latinoamericanos ha sido un objetivo fundamental de Fidel Castro, hasta por razones sentimentales. Por ello ha venido madurando una nueva política tercermundista que se puede derivar de las circunstacias concretas de la experiencia cubana. El paso fundamental se dio cuando Castro emprendió su política "estadista". Siendo de formación marxistaleninista, pudo apreciar que también a nivel de los Estados existía una lucha de clases: países ricos contra países pobres. A causa de estas consideraciones surge, entonces, la política exterior tercermundista cubana; y ha sido la cuidadosa aplicación de esta política, la que ha colocado a Cuba, hoy, en una posición de prestigio hemisférico.

Para Cuba, una política tercermundista no es nada nuevo, ya que los Estados Unidos siempre han sido su enemigo mortal. La política complementaria de un distanciamiento relativo de la URSS, como ya lo hemos señalado, se está realizando en una forma mucho más sutil. En todo caso, el acomodo tercermundista con la URSS es mucho más fácil que con las potencias capitalistas. ${ }^{37}$ En el fondo están en juego las aspiraciones del Tercer Mundo a un desarrollo económico sostenido. El llamado a un nuevo orden económico internacional con el fin de modificar las relaciones de intercambio desigual entre los países pobres y los paises ricos, deriva de esta aspiración; y Cuba no ha sido ajena a este movimiento. Pero Fidel Castro sabe muy bien que lograr acceso al mercado estadunidense puede representar una solución a los problemas económicos cubanos, especialmente en el campo

${ }^{36}$ Brasil también reconoce a la MPLA de Angola y ha estado incrementando sus relaciones diplomáticas y comerciales con los paises africanos, especialmente las excolonias portuguesas, desde mediados de los setenta. Coincidencialmente, las excolonias portuguesas están bajo regímenes socialistas y tienen lazos estrechos con Cuba.

${ }^{37}$ Fidel Castro, op. cit., p. 120-121. 
tecnológico. Desde esta perspectiva, el interés nacional cubano es restablecer relaciones diplomáticas y comerciales con los Estados Unidos. Con base en los hechos, los logros recientes de la política exterior cubana en América Latina y el área del Caribe, dan a Fidel Castro apoyo suficiente para llevar a los Estados Unidos a la mesa de negociaciones aunque la política de Reagan en Centroamérica tiende a negar a Cuba su prestigio hemisférico.

\section{La crisis centroamericana: 6 Contadora o la Doctrina Monroe?}

Centroamérica, entonces, es la clave de las futuras relaciones hemisféricas. Está en manos del presidente Ronald Reagan decidir el curso de esas relaciones. Negar a Cuba su merecido reconocimiento como potencia regional y desafiar los sentimientos latinoamericanos respecto a la situación centroamericana, podría representar una ofensa que la mayoría de los países latinoamericanos serian incapaces de soportar.

Contadora es la respuesta latinoamericana a la Doctrina Monroe: soluciones latinoamericanas a problemas latinoamericanos. Si la politica de Reagan continúa actuando bajo la premisa de que los Estados Unidos aün tienen capacidad para imponer una solución unilateral y militar en Centroamérica, es posible esperar una restructuración mayor del sistema de alianzas entre los países latinoamericanos y del Caribe. Además, podría acarrearle consecuencias mayores entre sus aliados y dividir la opinión pública interna. Como señaló Abraham Lowenthal:

...Una creciente intromisión de los Estados Unidos probablemente polarizará a la región, forzará movimientos nacionalistas de izquierda a un mayor acercamiento con Cuba y la Unión Soviética, minará la confianza de aliados europeos y latinoamericanos en el juicio político de los Estados Unidos y -lo más preocupante- fragmentará a este país involucrándonos en otro conflicto costoso sin un consenso nacional. ${ }^{38}$

Ya Reagan dio la espalda a los países de Contadora; Argentina desconfia de Washington y el movimiento nacionalista peruano, con Alan Garcia, se dirige a un enfrentamiento económico y político con los Estados Unidos. Fidel Castro no tiene nada que perder y todo por ganar, pero los Estados Unidos lo pueden perder todo.

38 Abraham Lowenthal, Washington Post, 3 de junio de 1984. 